\title{
Conceptualizing the Value Co-Destruction Process for Service Systems: Literature Review and Synthesis
}

\author{
Juuli Lintula \\ University of Jyväskylä \\ juuli.m.k.lintula@jyu.fi
}

\author{
Tuure Tuunanen \\ University of Jyväskylä \\ tuure@tuunanen.fi
}

\author{
Markus Salo \\ University of Jyväskylä \\ markus.t.salo@jyu.fi
}

\begin{abstract}
This study conceptualizes the notion of value codestruction by reviewing and synthesizing the scattered and scarce value co-destruction literature in interdisciplinary fields. Building on our synthesis, we outline a conceptual framework for the value co-destruction process consisting of three interrelated categories of key concepts. Our framework helps in identifying, analyzing and rectifying unwanted outcomes of a service process and highlighting the dynamic nature of value co-destruction in service systems.
\end{abstract}

\section{Introduction}

An essential goal when studying products, services and their design is to understand how value is formed. Vargo and Lusch [1,2] argue that the traditional goods-centered view, in which value is produced noninteractively without customer involvement, is expensive, perishable and nonresponsive to changing customer needs. They present a service-dominant (S-D) logic, in which the customer, possessing different resources in a specific context, becomes essentially involved with the value creation process $[1,2]$ as an active, well-informed and networked individual, aiming to have an influence on the company's functions by no longer merely accepting value propositions [3]. Customers interplaying with producers in the design and development of services, enables producers to gain a profound insight into what creates value for customers [4]. The interplay ends with the customer defining the final value in use in a service system [1], which refers to a configuration of people, technologies and other co-creation entities [5].

There has recently been debate about value cocreation in a subversive way, and the notion of value co-destruction has been introduced to the S-D logic literature [6-8] as an interplay of service systems resulting in a decline of well-being of at least one of the parties involved [8]. Understanding value codestruction is important as it may increase costs, customer loss, dissatisfaction and negative word of mouth
[35]. However, little research has addressed it [6-8], and the notion remains unclear [8], which motivates the purpose of this study: describing value codestruction behavior. This literature gap is addressed by our research question (RQ1): How can value codestruction be conceptualized? We further elaborate this with RQ2: What are the most centric and recurring foci and concepts in the value co-destruction literature? The main goal of this study is to synthesize the scattered research field of value co-destruction and to develop a conceptual framework for the value codestruction process. The usefulness of such synthesis and framework arises from guiding researchers towards understanding the concept and dimensions of value co-destruction. Furthermore, practitioners using the framework can prevent unwanted outcomes of a service process by steering and rectifying components prone to value co-destruction.

We start in the following section by introducing the concepts of value, value co-creation and value codestruction. In the next section, we introduce the research method applied in our study. Section four presents our findings, upon which a conceptual framework of value co-destruction is formed. We then conclude by discussing theoretical and practical implications of our study, followed by limitations and future research ideas.

\section{Background of S-D logic}

\subsection{Value}

Often, value has been described as an outcome of a trade-off, where benefits are pursued by sacrificing resources [9], and a division has been made between extrinsic and intrinsic value [10]. Use of information systems (IS) has been categorized into two types: utility (extrinsic value), which stands for productivityoriented, such as monetary benefit-driven, use, and hedonic (intrinsic value), which comprises pleasureoriented, e.g., enjoyment-driven, use [11]. Utilitarian value represents functional and practical means to an end, whereas hedonic values are the aspired toward end 
themselves with characteristics of fun, novelty, aesthetics and unexpectedness [12].

In the IS field it is argued that all IS need to provide users with some level of both hedonic and utilitarian value [13]. Here, the type of IS acts as a moderator: in utility-centric IS, the needed level of proposed utilitarian value is fairly high compared to hybrid IS, in which it is roughly even, or hedonic IS, which possess the lowest need for utilitarian value. After the needed level of utilitarian value is exceeded, the hedonic value becomes dominant and the driver of any type of IS [13].

In goods-dominant (G-D) logic, value consists of two phases: first, value is created by the producer, and second, value is consumed by the consumer [14, 15]. By contrast, Prahalad and Ramaswamy [16, 17] suggest interactive customer-producer involvement leads to cooperatively created value unique to the individual customer. Thus, consumers should be regarded as cocreators of experience or value [16] and consumerprovider interaction the key to value co-creation [17].

\subsection{Co-creation of value}

Vargo and Lusch [1] introduced S-D logic to marketing, positioning service as the foundation for the exchange instead of value. Service refers to the action of an entity benefiting itself or another entity [1, 15] by co-creating value-in-use, which is explained as an improvement in a system's well-being measured by the system's ability to fit in to its environment [18]. Consequently, the value of a service or a good only exists through customers' perceived contextual experiences enabled by the service or the good [19].

Thus, S-D logic comprises companies delivering customers value propositions, which they use to cocreate actual perceived value-in-use, which is always subjective and contextual [20]. Value co-creation, as an interactive process of parties co-creating value-in-use by integrating their own and utilizing others' resources [22-24], is the key function of S-D logic. It is a servicefor-service exchange occurring between involved parties, referred to as service systems, which are connected to each other by value propositions [18]. The goal of this service process is for the involved entities to benefit themselves and/or other entities involved by applying resources through particular interactive functions [18]. The used resources are divided into a) operant resources, which are tangible and substantial resources being acted upon by b) operand resources, such as knowledge and skills [21]. Value co-production, a subnotion of value co-creation, occurs when consumers integrate resources in the production of the core offering of the service, e.g., design or development [20]. While value co-production may be an essential part of co-creation of value, the co-creation process consists of companies delivering consumers value propositions, which customers use to co-create actual perceived value-in-use on a broader time frame and thus which cannot conceptually be limited solely to the coproduction of value [20].

Tuunanen et al. [22] have presented a conceptual framework for the design of consumer information systems explaining value co-creation as interaction between particular system value propositions and customer value drivers. The framework suggests that in successful co-creation of value, the offerings of the system are complemented by the value drivers of the user, and that value co-creation in the context of IS use occurs as an interplay between these two entities [22].

\subsection{Absence of value co-destruction in S-D logic literature}

In S-D logic literature, "service" fundamentally has an optimistic tone to it, and value is referred to in an intrinsically positive manner [8, 25]. Engaging in interactive value creation processes is also mainly explained in an unproblematic way [7]. The literature, however, overlooks potential negative consequences of a failed or errored co-creation process [26], and the notion of value co-destruction has not been thoroughly discussed, leaving it unclear and undefined [7, 8]. Plé and Chumpitaz Cáceres [8] state that since value can be co-created, it is logical that the interaction process between parties may also result in value co-destruction, and thus, they introduce and coin the concept of value co-destruction within the S-D logic framework.

Echeverri and Skålén [7], consistent with Plé and Chumpitaz Cáceres [8], argue value co-creation in S-D logic is an unrealistic conception. For instance, value co-destruction can occur in a service encounter where a bus driver informs customers regarding issues related to service but one or both parties fail to understand or pass on the message or keep relevant information to themselves [7]. Some earlier studies have also implied a negative side of value co-creation, or in other words, value being co-destroyed [7, 8]. For example, Prahalad and Ramaswamy [27] make a notion of the negative side of value co-creation, remarking that not all interactions between firms and customers are enjoyed or end up being perceived positively by the customer.

Furthermore, there are implications of value cocreation not always being the optimal function for both parties involved, and some depictions are made of circumstances under which no interaction is recommended [28]. Also, value imbalance between the customer and the provider and a devaluation process potentially resulting in value diminishment have been noted in the literature [19]. Etgar [29], in turn, has described value co-production as a process costing all 
involved parties something, highlighting the risk of the customer aiming to minimize its own costs of interaction and thus making the trade less worthwhile for the firm. He implies value diminishes due to the aspect of cost imbalance [29]. Consistent with the argument of Plé and Chumpitaz Cáceres [8], Echeverri and Skålén [7] further argue that interactive value formation not only occurs as value co-creation but also as value codestruction.

Later on, authors from various fields have, with empirical studies, also supported the notion of value co-destruction and it being as feasible an outcome of an interaction process as value co-creation [30-37, 47, $51,55,57,70,71]$. In the IS literature, early signs of both value creation and destruction are depicted through appearances of irrational behavior in IS development [38] and destructive behavior referred to as "the dark side," such as theft, sabotage and deception, in IS projects [39, 40]. Vartiainen and Tuunanen [6] state there is a lack of previous research discussing the negative consequences of design and possible negative occurrences during the value co-creation process, placing particular interest in studying it in the context of IS artifacts.

While researchers have recognized the notion of value co-destruction, the research still remains at an infant and scattered stage, calling to be synthetized and conceptualized in a framework as proposed in this study.

\section{Research method}

To synthesize value co-destruction literature and develop a conceptual framework, we conducted a literature review selecting relevant literature through seven steps (Table 1) and keyword searches in interdisciplinary databases: ProQuest, EBSCOhost, Emerald Insight and Google Scholar. Relevant articles were found in service science, marketing, management, IS, tourism and sports management fields. In the first search in ProQuest (step 1), 151 articles were found with the keyword "co-destruction," some addressing nonrelevant topics, such as chemistry or astronomy, whereupon the keywords "value" and "service" were added to the search to specify the context of the results.

The performed searches in four different databases (steps 2-5) with the keywords "co-destruction," "service" and "value" returned $68+47+197+474$ articles. All retrieved articles were assessed according to the following inclusion criteria: 1) The article focuses on studying value co-destruction (primary articles) or 2) The article presents occurrences of value codestruction (secondary articles). Of the retrieved articles, 15 met the criterion 1 and 14 the criterion 2 .
Table 1. Literature review process.

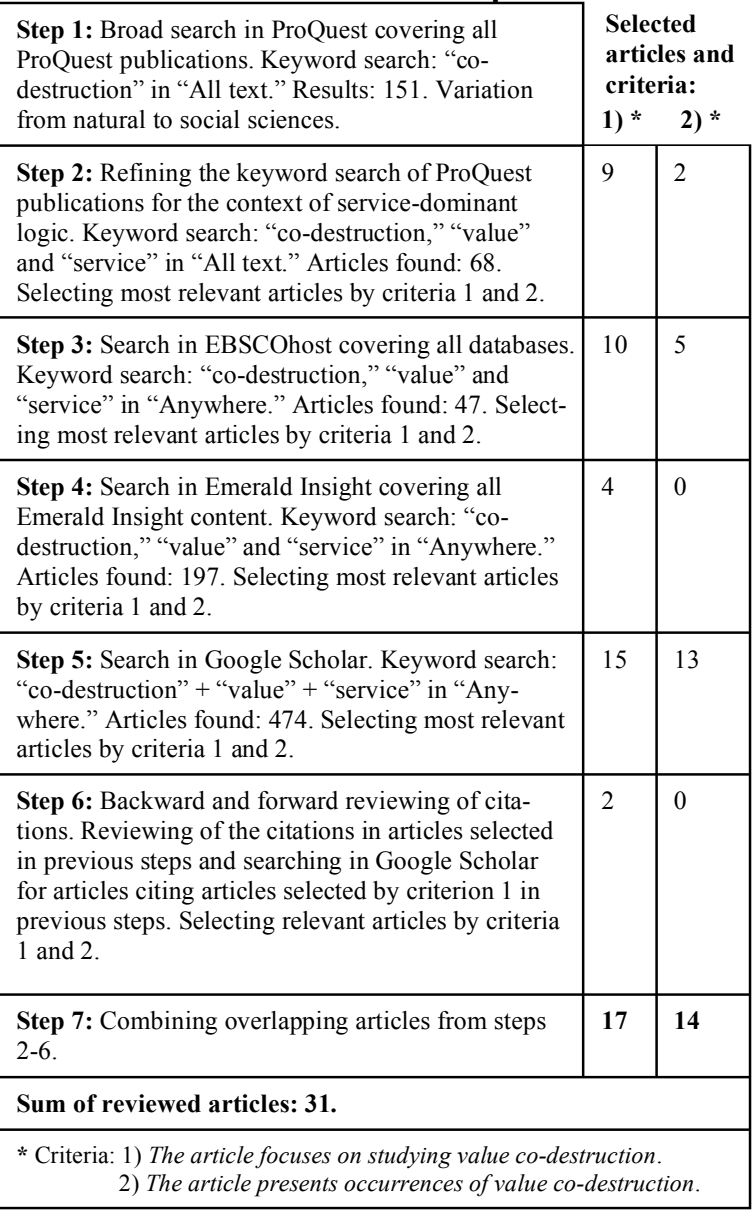

After steps 2-5, references and citation indexes of articles included by criterion 1 were assessed to find relevant articles going backward and forward with the same criteria (1 and 2). Two articles were added to the selection in this phase, both by criterion 1. Finally, a total of 31 articles were included in the review (17 articles by criterion 1 and 14 by criterion 2) (Table 1 ).

When analyzing the selected articles, our analysis was based on the primary articles that met criterion 1: we took extensive notes for each article in spreadsheet format and discussed them among the authors. We assessed the articles by their contexts, theories, methods, findings and the key concepts arising from presented explanations, predictions and outcomes of value co-destruction. These notes and assessments were backed up with the secondary articles that met criterion 2. Based on our extensive notes, handwritten memos and discussions, we arranged the key concepts into three overlapping dimensions (orientation, resources and perceptions) and their components. Finally, by arranging the components in the dimensions temporally according to their appearance in a service encounter, we formed a conceptual framework. 


\section{Findings: framework for value co- destruction process for service systems}

Recurring value co-destruction components, such as concepts, phrases, foci, similarities and differences, are acknowledged in this review. The key components of value co-destruction are tabulated in a conceptcentric [41] manner and categorized into three interrelated dimensions. These results are presented in Figure 1. The three overlapping dimensions of the framework,

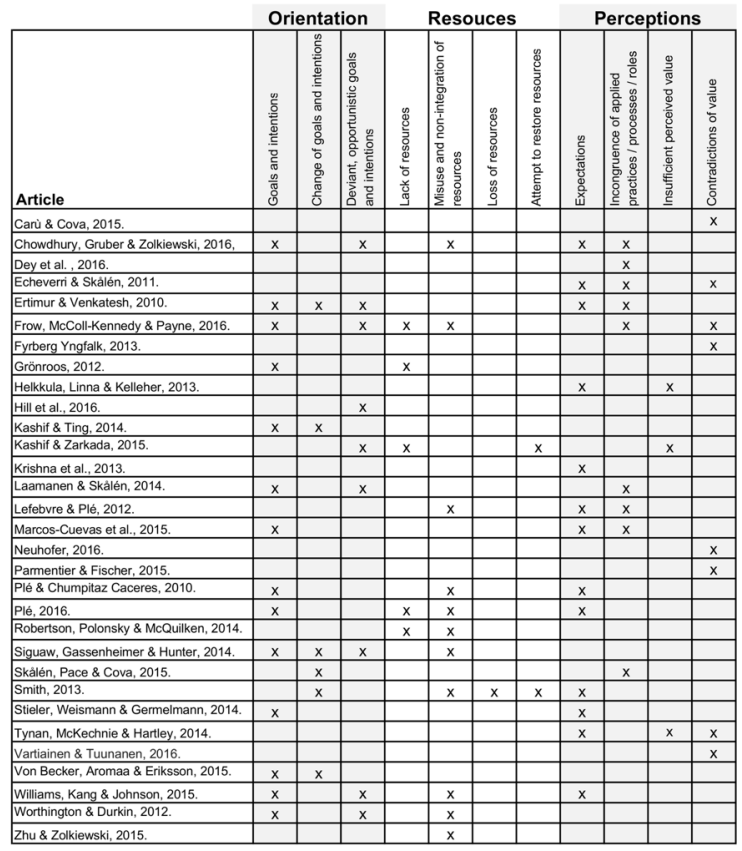

Figure 1. Results of the literature review.

Orientation, Resources and Perceptions, all have components, which appear at different temporal points: before, during and/or after the service process.

Orientation in our categorization includes intentions and goals, which evolve throughout and after the service process. In the Resources dimension, value codestruction may originate from lack of resources, potentially leading to misuse and/or loss of resources during the service process, which then may lead to attempts to restore lost resources after the interaction process. The Perceptions dimension sets prior expectations in a triggering role for value co-destruction. For instance, perceived incongruence of applied practices during service use may originate from inconsistencies in expectations of the interacting parties. Unrealistic prior expectations may also lead to insufficient perceived value and value contradictions during service use and after. The components are interrelated and may occur linearly as well as inter-dimensionally and in retroactive loops. For instance, lack of resources, such as knowledge or access to information, may compound unrealistic expectations, and the attempt to restore resources may trigger a new retroactive value codestruction loop. The proposed framework (Figure 2) categorizes value co-destruction dimensions and components, hence, explaining the phenomenon of value co-destruction. Contents of each dimensionorientation, resources and perceptions-are next reviewed one by one.

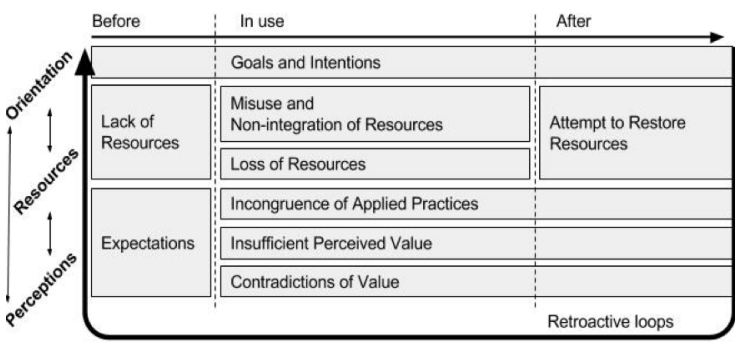

Figure 2. Framework for value codestruction process for service systems.

\subsection{Orientation}

4.1.1. Goals and intentions. Plé and Chumpitaz Cáceres [8] state value co-destruction may result from an accidental or intentional misuse of resources in an interaction process between service systems; thus, value co-destruction may be intended or unintended. Unintentional value co-destruction occurs when intended value co-creation accidentally results in diminishment of a system's well-being. Intentional value codestruction, in turn, refers to a service system intentionally misusing resources in order to gain more benefit - described as well-being - and capacity for adaptiveness for itself, to the detriment of those of another system [8]. Intentions to co-destroy or not to co-create value $[8,23,36,49,50,63]$, opportunism or deviancy $[37,47-49,51-54,56]$, and changes in intentions [31, $35,48,55-57]$ are implied to herald value codestruction in the literature.

Kashif and Zarkada [47] state "intentional misuse is the existence of deliberate value imbalances." Furthermore, Vartiainen and Tuunanen [6] state value is co-destroyed both knowingly and unknowingly in the context of technology-assisted geocaching, in which some participants are aware, while others are unaware, of the negative value effect of their actions while pursuing positive value. For instance, a geocacher may experience nature at its purest while consuming it at the same time [6].

Ertimur and Venkatesh [48] argue deliberate opportunistic behavior in co-production of value is mainly driven by incongruence of goals under the conditions of information asymmetry or social disagreement. For instance, if an automobile producer engages consumers 
to co-production of commercial online video material aiming to develop a particular brand image, the involved consumers may have incongruent goals in engaging and actually use the opportunity to promote their own agenda, such as environmental activism [48]. There is information asymmetry as the provider cannot know if a consumer's agenda is conflicted with their own goals, which could lead to value co-destructive outcomes in form of i.e. brand image weakening.

The evolution of the service process is often unpredictable as well as conflicted [57] and opportunism is found to occur in interactions when it is or becomes profitable and feasible [48]. Echeverri and Skålén [7] depict four subject positions, orientating roles that actors step into in the course of the service interaction. Subject positions portray orientations of parties and may change from creative to destructive or vice versa causing mixed service processes [7]. Along with a destructive change of the subject position, a coherent value co-creation praxis changes into reductive value co-formation, where the ultimate outcome is codestructive [7]. Reductive value co-formation occurred, for instance, when a public transportation driver first aimed to co-create value welcoming a customer on board, followed a value co-destructing reply from the customer complaining loudly about the bus not being on schedule. This also made the bus driver talk back to the customer in an unprofessional and co-destructive manner [7]. Von Becker et al. [57] conclude that the relationship between co-creative and co-destructive behaviors is dynamic, and based on evidence of a studied consulting situation, individual actors involved in the service interaction lack control over the collectively formed value regardless of individual intentions [57].

\subsection{Resources}

4.2.1. Lack of resources. Value co-creation is a resource integration process, which requires resource inputs from both parties involved. In case one or both service systems lack resources, such as time or skills to engage in value co-creation, the process may fail, resulting in diminishment of well-being for one or both parties [8, 63]. Also, lack of provided information, such as poor quality of communication between parties, may appear as lack of resources in a value coformation process [34, 51]. Consistent with this, Kashif and Zarkada [47] state that involving consumers in the production process increasingly leads to accidental value co-destruction because consumers lack sufficient knowledge to successfully take part in the process. For instance, Robertson et al. [34] studied value codestruction in the context of online self-diagnosis and discovered value is co-destructed by both the provider and the user due to initial lack of resources. Consumers using self-diagnosis websites often couldn't comprehend the provided information due to lack of resources, such as sufficient medical knowledge, and secondly, providers often lacked resources to provide users with complete and understandable information [34]. Due to initial lack of such resources, false and incomprehensible self-diagnoses occurred with a negative impact on customers' well-being, and thus, value was codestructed in the interactions [34].

4.2.2. Misuse and non-integration of resources. Plé and Chumpitaz Cáceres [8] argue value codestruction occurs due to the misuse of available resources in the interaction process between service systems, and such misuse of resources as a manifestation of value co-destruction has also been supported by other studies [25, 33-35, 37, 48-51, 53, 56, 58]. Plé and Chumpitaz Cáceres [8] place the concept of value destruction-through-misuse in the S-D logic framework opposite to value-in-use, as an outcome of a service system misusing its own or another service system's resources or different service systems both misusing their own and/or each other's resources. The misuse results in value co-destruction for at least one service system and is explained as at least one of them failing to integrate or apply the available operant and operand resources in an appropriate or expected way from the perspective of the other service system [8]. For example, a web store company co-destructed value by promising and failing to home deliver a purchased laptop on a specific date and time. The company codestructed value by misusing their own technology resources (delivery system) costing the customer resources such as temporal, material and financial [35]. Consequently, misuse referring to resource integration, Plé [23] adopts the term misintegration for the action.

An intentional choice not to collaborate may also lead to non-integration of resources [23]: for example, the online diagnosis service user experiencing lack of essential knowledge on how to search for medical information with correct terminology, could decide to stop using the service (non-integrate), which would result in value co-destruction for the customer in form of not gaining expected information of the service use.

4.2.3. Loss of resources. As engaging in a value cocreation process may require an investment of a high amount of resources, customers' value perceptions may be impacted in a negative way [59]. Drawing on COR theory [44, 45] Smith [35] suggests gain and loss of individual resources, such as material, condition, self and energies, link to well-being and can also help in acquiring other resources, such as social status, selfesteem or transportation. Expectations are in a key role when it comes to the perceived loss of resources [35, 
$44,60]$ and thus, value co-destruction [35]. For instance, a customer engaging in co-production of a service design process is expecting to be investing resources, such as time and knowledge, to the project and on the other hand, receiving other resources, such as networking or access to use of the designed product. If expected resources are not gained or the expected loss of resources is exceeded, value co-destruction occurs [35]. From the customer point of view, loss of resources (value co-destruction) would occur in four scenarios: 1) the provider is unexpectedly not able to fulfill the expected resource offer, 2) expected resources are not gained, 3) customer loses more resources than expected or 4) "A combination of the above" [35].

4.2.3. Attempt to restore resources. The outcome of a value co-destructive service process can be seen as primary loss of resources experienced by at least one of the service systems [35]. After perceiving unexpected loss of resources, a service system may deliberately take on negative intentions and engage in codestructive actions as an attempt to restore lost resources, which may then lead to secondary loss of resources for one or multiply service systems involved [35]. For instance, a customer using an online food ordering service and not receiving her order on time due to a system failure, experiences loss of resources such as monetary, time and self-efficacy. This may lead to taking on coping mechanisms [35, 47], such as complaining directly and badmouthing the company to other consumers in angry Twitter messages, in order to regain resources, such as monetary and other compensation and peer support. This action may result in secondary resource loss [35] for the company (loss of reputation) and the customer (loss of time), yet, the customer may also be able to regain resources, such as self-efficacy, monetary and peer support [35]. Plé suggests the process is dynamic and consists of retroactive process loops, value co-destruction and cocreation being steps on the way toward the final outcome, which may be co-creative or co-destructive [23].

\subsection{Perceptions}

4.3.1. Expectations. Service encounters are cocreation entities, where in order to co-create value, parties must meet or exceed each other's expectations [62]. Hence, if both parties' needs are not fulfilled, the attempt of co-creation fails in a deficit, and value codestruction occurs [36]. One of the service systems not receiving the expected value of the service encounter (the other party failing to play the expected role) may lead to intentional misbehavior and value codestruction [47]. Hence, the adequate level of co- created value in a service encounter is defined through expectations [35], and whether the expected outcome is reached or not may define if value is co-created or codestroyed [8]. Multiple studies imply a party in a service encounter has expectations of the nature or the level of the other party's actions or the service outcome $[7,23,25,30,49-51,53]$. From one service system's point of view, an inappropriate or unexpected way of another system integrating and applying available resources can result in the concept of value destruction-through-misuse for the service system [7, 8]. Smith [35] suggests that value co-destruction occurs even when the pursued enhancement of well-being has not been quite fully met, as the expected increase of well-being, such as expected pleasure of service use, remains unachieved, but invested resources, such as time spent on using the service, are lost.

4.3.2. Insufficient perceived value. Perceived value is linked to prior experiences and expectations based on them, and consequently, individual actors engaging in a service interaction, expect a certain value dimension to be met based on their experience [36]. The expected level of service not being met [36], and non-preferred value being co-created $[30,65]$ during service use could lead to value co-destruction. Such value codestruction could occur for instance, when a bank customer hoping to open a new bank account was asked to wait for more than two hours in order to get the absent manager to sign a form and thereby submit the application [47]. Such situation could end in the customer having the account opened, but not in the expected time frame, which would lead to insufficient co-created value and ultimately, value co-destruction.

4.3.3. Incongruence of practices. Echeverri and Skålén [7] draw on practice theory stating interactive value formation - either value co-creation or codestruction - proceeds from the actions of service systems drawing upon congruent or incongruent elements of practices. Drawing on Schau et al. [64], they depict three such elements of practices: 1) Procedures, 2) Understandings, and 3) Engagements, which are drawn upon according to prior conceptions, and when such conceptions of practitioners are incongruent, value is co-destroyed [7]. For example, a bus driver greeting a customer in an overly cheerful manner may have a co-destructive effect as the greeting may not have been adapted to the sensitive personal situation of the customer. This occurrence would translate to value co-destruction through drawing on incongruent engagements [7]. Inversely, a process of practitioners drawing on congruent procedures, understandings and engagements leads to value co-creative outcomes [7, 54]. 
4.3.4. Contradictions of value. According to Plé and Chumpitaz Cáceres [8], the process of value codestruction may lead to differential results for separate service systems, and the level of co-destructed value resulting from the interactional process may not be the same for all systems involved. Value is measured by the system's ability to adapt to the environment [19]; thus, value being co-destructed may lead to different service systems fitting differentially into their environments, and for one service system, the interaction may co-create value-in-use, while for the other, it may cause value destruction-through-misuse [8]. For example, this was what happened with audience dissipation in relation to the America's Next Top Model show [32], where the self-branding efforts of the participants of the television show resulted in contradictions in perceived value by the television viewers. Contradictions in value co-creation outcomes can be interpreted from findings and discussions of some reviewed articles [51, $65,66]$ and a duality in value co-formation has been recognized [8, 32, 66]. For instance, football hooliganism could be converted into commercial opportunities, achieving value co-creative outcomes from value codestructive process attempts [66].

Echeverri and Skålén [7] argue that a value coformation process can consist of both value co-creation and co-destruction. They depict four types of praxis through which value either forms or diminishes in an interactive service process: 1) Reinforcing value cocreation, 2) Recovery value co-creation, 3) Reductive value co-formation and 4) Reinforcing value codestruction [7]. Reinforcing value co-creation and Reinforcing value co-destruction are coherent in their value formation processes, as Recovery value cocreation and Reductive value-co-creation offer a mixed process view. A mixed process begins with practitioners either drawing on congruent or incongruent elements of practices, followed by an alteration to contradictory drawings, and thus leading an initially cocreative process to co-destructive outcomes or vice versa. However, according to Echeverri and Skålén [7], regardless of the nature of the process, the outcome cannot be contradictory, as it always results either in value co-creation or co-destruction [7].

Vartiainen and Tuunanen [6] introduce the topic of value co-destruction to IS literature and, inconsistent with Echeverri and Skålén [7], discover simultaneous value co-creation and value co-destruction, identifying two poles in the results of the studied IS artifact of geocaching. They apply the concept of contradictions identifying four contradictive results, finding that both the value creation pole and the value destruction pole exist in an interactive value formation process, and that value can be co-destroyed while positive value is pur- sued [6]. For instance, geocachers' values of socializing and strong sense of community can contradict with the game's premise of being competitive. Contradictory outcomes of value co-formation are explained by the link between the IS artifact's sub-systems enabling simultaneous co-creating and co-destructing of value. It is discovered that an IS artifact may be inherently contradictory, and "through differentiation and integration, both poles reinforce each other, and through development of links, it is possible to create solutions for practical conflicts and eruptions" [6].

\section{Implications and concluding remarks}

This study contributes by addressing the scarce and scattered value co-destruction literature by conducting a review of 31 articles and developing a conceptual framework for the value co-destruction process for service systems (see Table 1 and Fig. 1). As an answer to our research questions, we synthesized the literature, revealing value co-destruction as an important yet recently discovered phenomenon lacking versatile empirical research and consensus as well as distinguishing recurring concepts and foci of the phenomenon and its dimensions.

We divided the key concepts and foci into three interrelated dimensions: orientation (goals and intentions), resources (lack, misuse, non-integration and loss of resources and attempt to restore resources) and perceptions (expectations, incongruence of applied practices, insufficient perceived value and contradictions of value), and examined their properties in relation to time. As a result, we were able to present a preliminary and conceptual framework of the value co-destruction process for service systems (see Fig. 2). Our synthesis and conceptual framework are particularly useful in this early phase of value co-destruction research because they relate the first, relatively fragmented studies to each other.

As for theoretical implications, our study extends the prior knowledge by presenting a literature review and a conceptualization of value co-destruction for S-D logic. To our knowledge, this is an original contribution, as value co-destruction has not been conceptualized this way in prior literature. With our study, we aim to provide researchers a tool - the framework (Fig. 2) - to understand the dimensions and central components of value co-destruction. Furthermore, our framework particularly highlights the dynamic nature of value co-destruction: there are crucial differences in how value co-destruction is shaped regarding the different temporal dimensions of the interaction process (before, in use, after). This can be applied, for example, within the different temporal phases of a service 
process to investigate differences in what kind of attention is needed to support co-creation of value.

In addition to the theoretical contribution of conceptualizing value co-destruction, this study also aims to give firms and service designers important insights on the value co-destructive side of the interactive service process in order for them to identify and avoid the worst pitfalls. Understanding the potential of value codestruction is important in order to identify, analyze and rectify unwanted outcomes of a service process [8] in a similar way that it is fundamental to competitiveness to gain profound insights on creating value for and co-creating value with customers [4]. We see that our conceptual framework can help practitioners who design and implement services in channeling attention to specific components such as user expectations [8] and value perceptions [35], that are especially vulnerable to value co-destruction. By taking notice of the varied risks of co-creation practices before, after and during the course of a service encounter, a number of pitfalls could be avoided. For example, ensuring users receive sufficient prior information of the offering, time frame and requirements of the service and providing access to sufficient information during use may increase congruence of practices and reduce negative outcomes of the service process. Such actions may prevent service providers from losing their customers and suffering from negative word of mouth.

There are certain limitations related to this study. First, the article acquisition completed by a keyword search limits this study because some potentially relevant articles may recognize the studied phenomenon but use different terminology than that of S-D logic and value co-destruction. Second, articles studying the problems and challenges of value co-creation may offer additional contributions to the literature of value co-destruction but were excluded from this review as a result of the outlining of the data acquisition to the keywords "co-destruction," "value" and "service." Third, some critical viewpoints to value co-creation (e.g., the ethics of consumer exploitation) have been taken in marketing literature, such as [67-69]. Finally, the method of selecting and categorizing key components to develop a conceptual framework is by nature subjective and interpretative and thus limits this study.

While literature discussing co-destruction of value is scattered and lacking versatile empirical studies, we recognize that some noteworthy viewpoints remain unaddressed. This sets an arena for future studies. Some questions remain with respect to our framework, for instance, how interrelated the categories and components are when it comes to the process of value codestruction. For instance, the perceptions and resources categories were highly related, as prior expectations defined the acceptable loss of resources during a ser- vice encounter [35]. More research is therefore needed to strengthen our framework by studying whether some of the components are more dominant than others, cross-affecting each other, or if some of the components can be more easily rectified than the others. Future studies could also take a one-component-centric approach, studying thoroughly the relations of a specific component, such as lack of resources, to all other components.

Our conceptual framework can benefit future research and practitioners in piecing together factors causing co-destruction in service encounters and determining significant temporal points for rectifying actions. Analyzing value co-formation processes using our framework may help in breaking down dimensions of value co-destruction. For instance, value codestruction in IS use could be observed through a specific category (orientation, resources or perceptions), and relations between categories could be studied in order to find which category and components are most likely to drive negative outcomes in different contexts, user groups or types of IS. Through empirical studies, categories could also be ranked by their effects on value co-formation (from most to least likely to increase co-destructive outcomes). Consequently, an amplified and interrelated framework of value codestruction could be built in order to provide system designers correcting guidelines for avoiding codestruction of value among users of varied groups, contexts or system types.

\section{References}

[1] Vargo S.L. and Lusch R.F., "Evolving to a new dominant logic for marketing," Journal of Marketing (68:1), 2004, pp. 1-17.

[2] Vargo S.L. and Lusch R.F., "Service-dominant logic: continuing the evolution," Journal of the Academy of marketing Science (36:1), 2008, pp. 110.

[3] Prahalad C.K. and Ramaswamy V., "Co-creating unique value with customers," Strategy \& leadership (32:3), 2004, pp. 4-9.

[4] Flint D.J. and Mentzer J.T., The Service-Dominant Logic of Marketing: Dialog, Debate, and Directions, Armonk, NY: ME Sharpe, 2006, pp. 139149 .

[5] Maglio P.P., Vargo S.L., Caswell N. and Spohrer J., "The service system is the basic abstraction of service science," Information Systems and ebusiness Management (7:4), 2009, pp. 395-406.

[6] Vartiainen T. and Tuunanen T., "Value CoCreation and Co-Destruction in an IS Artifact: Contradictions of Geocaching," 49th Hawaii International Conference on System Sciences (HICSS), 2016, pp. 1266-1275. 
[7] Echeverri P. and Skålén P., "Co-creation and codestruction: A practice-theory based study of interactive value formation," Marketing Theory (11:3), 2011, pp. 351-373.

[8] Plé L. and Chumpitaz Cáceres R., "Not always cocreation: introducing interactional co-destruction of value in service-dominant logic," Journal of Services Marketing (24:6), 2010, pp. 430-437.

[9] Zeithaml V.A., "Consumer perceptions of price, quality, and value: a means-end model and synthesis of evidence," The Journal of marketing, 1988, pp. 2-22.

[10] Holbrook M.B., Consumer value: A framework for analysis and research, Psychology Press, Routledge London, 1999, pp. 1-28.

[11] Van der Heijden H., "User acceptance of hedonic information systems," MIS quarterly, 2004, pp. 695-704.

[12] Tuunanen T., "Is It Time to Re-Evaluate the Connection Between Bounded Rationality and Requirements Elicitation?", In the proceedings of AMCIS, 2006, Acapulco, Mexico.

[13] Valkonen K., Lindström N., Natunen L., Isoviita R. and Tuunanen T., "Balance of Hedonic and Utilitarian Values in Information Systems Use," In the proceedings of SCIS, Nordic Contributions in IS Research, 2015, pp. 165-176.

[14] Grönroos C., "Adopting a service logic for marketing," Marketing theory (6:3), 2006, pp. 317-333.

[15] Vargo S.L. and Lusch R.F., "Why "service"?" Journal of the Academy of marketing Science (36:1), 2008, pp. 25-38.

[16] Prahalad C.K. and Ramaswamy V., "The Cocreation Connection", Booz. Allen \& Hamilton, 2002, pp. 50-61.

[17] Prahalad C.K. and Ramaswamy V., "Co-creation Experiences: The Next Practice in Value Creation," Journal of interactive marketing (18:3), 2004, pp. 5-14.

[18] Vargo S.L., Maglio P.P. and Akaka M.A., "On value and value co-creation: A service systems and service logic perspective," European management journal (26:3), 2008, pp. 145-152.

[19] Woodruff R.B. and Flint D.J., "Marketing's service-dominant logic and customer value," The service-dominant logic of marketing: Dialog, debate, and directions, 2006, pp. 183-195.

[20] Lusch R.F. and Vargo S.L., "Service-dominant logic: reactions, reflections and refinements," Marketing theory (6:3), 2006, pp. 281-288.

[21] Lusch R.F. and Vargo S.L., "Service-dominant logic as a foundation for a general theory," (406), 2006.

[22] Tuunanen T., Myers M. and Cassab H., "A conceptual framework for consumer information systems development," Pacific Asia Journal of the Association for Information Systems (2:1), 2010.

[23] Loïc Plé, "Studying customers' resource integration by service employees in interactional value cocreation," Journal of Services Marketing (30:2), 2016, pp. 152-164.
[24] Grönroos C. and Voima P., "Critical service logic: making sense of value creation and co-creation," Journal of the Academy of Marketing Science (41:2), 2013, pp. 133-150.

[25] Lefebvre I. and Plé L., Emergence of value codestruction in B2B context (working paper), 2012.

[26] Dong B., Evans K.R. and Zou S., "The effects of customer participation in co-created service recovery," Journal of the Academy of Marketing Science (36:1), 2008, pp. 123-137.

[27] Prahalad C.K. and Ramaswamy V., The future of competition, Harvard Business School Press, Boston, MA, 2004.

[28] Jaworski B. and Kohli A.K., "Co-creating the voice of the customer," The service dominant logic of marketing: Dialog, debate and directions, 2006, pp. 109-117.

[29] Etgar M., "Co-production of services," The Service-Dominant Logic of Marketing, 2006, ME Sharpe, Armonk, NY, pp. 128-138.

[30] Helkkula A., Linna M. and Kelleher C., "Health, cost, prevention and cure-value and value cocreation in public healthcare," Naples Forum on Service, Naples, Italy.

[31] Per Skålén, Pace S. and Cova B., "Firm-brand community value co-creation as alignment of practices," European Journal of Marketing (49:3), 2015, pp. 596-620.

[32] Parmentier M. and Fischer E., "Things Fall Apart: The Dynamics of Brand Audience Dissipation," Journal of Consumer Research (41:5), 2015, pp. 1228-1251.

[33] Zhu X. and Zolkiewski J., "Exploring service failure in a business-to-business context," Journal of Services Marketing (29:5), 2015, pp. 367-379.

[34] Robertson N., Polonsky M. and McQuilken L., "Are my symptoms serious Dr Google? A resource-based typology of value co-destruction in online self-diagnosis," Australasian Marketing Journal (22:3), 2014, pp. 246-256.

[35] Smith A., "The value co-destruction process: a customer resource perspective," European Journal of Marketing (47:11/12), 2013, pp. 1889-1909.

[36] Stieler M., Weismann F. and Germelmann C.C., "Co-destruction of value by spectators: The case of silent protests," European Sport Management Quarterly (14:1), 2014, pp. 72-86.

[37] Worthington S. and Durkin M., "Co-destruction of value in context: Cases from retail banking," The Marketing Review (12:3), 2012, pp. 291-307.

[38] Hirschheim R. and Newman M., "Symbolism and information systems development: myth, metaphor and magic," Information Systems Research (2:1), 1991, pp. 29-62.

[39] Rost J. and Glass R.L., "The impact of subversive stakeholders on software projects," Communications of the ACM (52:7), 2009, pp. 135-138.

[40] Rost J. and Glass R.L., "The dark side of software engineering: evil on computing projects", John Wiley \& Sons, 2011. 
[41] Webster J. and Watson R.T., "Analyzing the past to prepare for the future: Writing a literature review," MIS quarterly (26:2), 2002, pp. 13-23.

[42] Diener E.E., Suh E.M., Lucas R.E. and Smith H.L., "Subjective Well-being. three decades of progress," Psychological Bulletin (125:2), 1999, pp. 276-302.

[43] Folkman S. and Lazarus R.S., "If it changes it must be a process: study of emotion and coping during three stages of a college examination.” Journal of personality and social psychology (48:1), 1985, pp. 150-170.

[44] Hobfoll S.E., "Conservation of resources: A new attempt at conceptualizing stress." American psychologist (44:3), 1989, pp. 513-524.

[45] Hobfoll S.E., "Social and psychological resources and adaptation." Review of general psychology (6:4), 2002, pp. 307-324.

[46] Vargo S.L. and Lusch R.F., "It's all B2B... and beyond: Toward a systems perspective of the market," Industrial Marketing Management (40:2), 2011, pp. 181-187.

[47] Kashif M. and Zarkada A., "Value co-destruction between customers and frontline employees: A social system perspective," International Journal of Bank Marketing (33:6), 2015, pp. 672-691.

[48] Ertimur B. and Venkatesh A., "Opportunism in coproduction: Implications for value co-creation," Australasian Marketing Journal (18:4), 2010, pp. 256-263.

[49] Chowdhury I.N., Gruber T. and Zolkiewski J., "Every cloud has a silver lining-Exploring the dark side of value co-creation in B2B service networks," Industrial Marketing Management (55), 2016, pp. 97-109.

[50] Marcos-Cuevas J., Enz M., Bastl M. and Johnson M., "Marriage of Inconvenience: Value CoDestruction in an Inter-Dependent Supply Chain Relationship," Marketing Dynamism \& Sustainability: Things Change, Things Stay the Same.... Springer International Publishing, 2015, pp. 378381.

[51] Frow P., McColl-Kennedy J.R. and Payne A., "Cocreation practices: Their role in shaping a health care ecosystem," Industrial Marketing Management, 2016.

[52] Hill R.P., Capella M.L., Rapp J.M. and Gentlemen G., "Antiservice as Guiding Maxim: Tough Lessons From a Maximum Security Prison," Journal of Service Research (19:1), 2016, pp. 57-71.

[53] Williams B.N., Kang S. and Johnson J., "(Co)Contamination as the Dark Side of Co-Production: Public value failures in co-production processes," Public Management Review, 2015, pp. 1-26.

[54] Laamanen M. and Skålén P., "Collectiveconflictual value co-creation: A strategic action field approach," Marketing Theory, 2014, pp. 1-21.

[55] Kashif M. and Ting H., "Service-orientation and teaching quality: business degree students' expectations of effective teaching," Asian Education and Development Studies (3:2), 2014, pp. 163-180.
[56] Siguaw J.A., Gassenheimer J.B. and Hunter G.L., "Consumer co-creation and the impact on intermediaries," International Journal of Physical Distribution \& Logistics Management (44:1), 2014, pp. 622.

[57] Von Becker S., Aromaa E. and Eriksson P., "Client-consultant interaction: the dynamics of and conflicts in value co-creation and co-destruction," International Journal of Services Technology and Management (21:1-3), 2015, pp. 40-54.

[58] Carù, A. and Cova B., "Co-creating the collective service experience," Journal of Service Management (26:2), 2015, pp. 276-294.

[59] Kellogg D.L., Youngdahl W.E. and Bowen D.E., "On the relationship between customer participation and satisfaction: two frameworks," International Journal of Service Industry Management (8:3), 1997, pp. 206-219.

[60] Woodruff R.B., "Customer value: the next source for competitive advantage," Journal of the academy of marketing science (25:2), 1997, pp. 139-153.

[61] Inman J.J., "Regret regulation: Disentangling selfreproach from learning," Journal of Consumer Psychology (17:1), 2007, pp. 19-24.

[62] Oliver R.L., "Co-producers and co-participants in the satisfaction process," 2006, pp. 118-127.

[63] Grönroos C. "Conceptualising value co-creation: A journey to the $1970 \mathrm{~s}$ and back to the future." Journal of Marketing Management 28.13-14, 2012, pp. 1520-1534.

[64] Schau H.J., Muñiz Jr A.M. and Arnould E.J., "How brand community practices create value," Journal of Marketing (73:5), 2009, pp. 30-51.

[65] Tynan C., McKechnie S. and Hartley S., "Interpreting value in the customer service experience using customer-dominant logic," Journal of Marketing Management (30:9-10), 2014, pp. 1058-1081.

[66] Fyrberg Yngfalk A., “'It's not us, it's them!'Rethinking value co-creation among multiple actors," Journal of Marketing Management (29:9-10), 2013, pp. 1163-1181.

[67] Zwick D., Bonsu S.K., Darmody A.: Putting Consumers to Work: 'Co-creation' and New Marketing Govern-Mentality. Journal of Consumer Culture 8, 2008, pp. 163-196.

[68] Cova B., Dalli D.: Working Consumers: The Next Step in Marketing Theory? Marketing Theory 9, 2009, pp. 315-339.

[69] Bonsu S. K., Darmody A.: Co-creating Second Life Market-Consumer Cooperation in Contemporary Economy. Journal of Macromarketing 28, 2008, pp. 355-368.

[70] Dey, B. L., Pandit, A., Saren, M., Bhowmick, S., \& Woodruffe-Burton, H. "Co-creation of value at the bottom of the pyramid: Analysing Bangladeshi farmers' use of mobile telephony." Journal of Retailing and Consumer Services 29 2016, pp. 40-48.

[71] Krishna, A., Davis L., \& Sunishtha, D. "Cocreation channel: A concept for paradigm shift in value creation." Journal of Management Science and Practice 1.1, 2013, pp. 14-21. 